\title{
Design and development of the interactive courseware based on SCORM standard
}

\author{
Jing $\mathrm{Yu}^{1, \mathrm{a}}$ and Hang Guo ${ }^{2, \mathrm{~b}}$ \\ ${ }^{1}$ Department of Avionics Engineering, the first aeronautical college of air force, Henan, Xinyang, \\ China \\ ${ }^{2}$ Department of Armament Engineering, the first aeronautical college of air force, Henan, Xinyang, \\ China \\ a65321165@qq.com, bguohang0001@126.com
}

Keywords: interactive courseware; SCORM standard; distance learning system; SCORM courseware.

\begin{abstract}
The main requirements of the design and development of interactive courseware for distance learning system are discussed in the paper. Firstly the system structure of SCORM standard and its constitution are introduced, and then the advantages of constructing SCORM courseware are proposed. This paper focuses on the development of learning management system based on SCORM standard, and discusses the architecture of learning management system, the elements of SCORM and the key technologies of the development of this system. The developed interactive courseware is portable, reusable, renewable and easy to operate, and it can be used to develop distributed training system for distance learning system.
\end{abstract}

\section{Introduction}

With the development and popularization of the public network transmission platform, the learning system of distance learning network has become the main direction of the development of higher occupation education. It can effectively reduce the cost of learning, and improve the quality of learning. The design and development of interactive courseware based on the Sharable Content Object Reference Model (SCROM) standard is an important component of this system, which can be used for teaching, teaching guidance and test, and this system has advantages such as reuse, easy management, easy to update and interoperability..

\section{The requirements of the design and development of interactive courseware}

The requirements in the development process must follow two principles: one is to establish a public courseware running environment, which is also named learning management system; the other is to build an effective standard to establish courseware description framework, resource description and organization of courseware standards. The international general SCORM standard is also based on these principles [2].

2.1 Interactive courseware can be combined according to different learning and learning levels.

The trainees of higher vocational education are various, and the training level is divided into primary, intermediate, advanced and so on. Different trainees and training levels both overlap the training content, and they also have different training content and evaluation system, which requires interactive courseware must have flexible teaching ability. The construction of simple or complex learning mode for the training of individuals or groups according to specific needs will be independent of various teaching components. A variety of applications through tailored flexible learning options reorganization should by applied to different levels of personnel and levels.

2.2 The interactive courseware can meet the different needs of centralized training and distributed learning.

Centralized training depends on the integration of the training center of the CBT classroom, and the teacher can play courseware in the CBT classroom, or interact in the teacher workstation using 
the courseware with the student workstations. Distributed learning depends on the distance learning network, which is responsible for providing the teaching equipment to form a distance learning network. This requires interactive courseware has a strong versatility and easy accessibility. It can deploy the same teaching resources to run in different platform environment, and has the ability to associate with catalog and content data repository in remote location.

2.3 The resources of the interactive courseware can be reorganized and updated.

Interactive courseware content mainly consists of professional courses, professional foundation courses and basic courses, together with a large number of teaching PPT, video materials, teaching software and other learning resources. The training content can be adjusted in real time with the learning progress, learning level and professional needs, and ensure the effective implementation of all learning resources in the entire distance learning system.

\section{SCORM standard system structure}

SCORM is a distance education standard developed by the America's teaching management system, the global learning alliance, which has been developed since 1997. It has become the international standard in the field of distance education. The SCORM standard describes a deployment model, which provides widely accepted and implemented e-learning standards. The learning content object has a high level of accessibility, adaptability, affordability, persistence, interoperability, reusability.

LMS is the learning technology system specification proposed by the global learning Union, and it is a influential industry standard. LMS has a series of functions, such as sending, tracking, reporting, evaluation and management of learning content, learning progress of learners, the interaction between learners and so on. The SCORM focuses on the content the main LMS interfaces, and they are not related to the special features and performance of one LMS. In SCORM, LMS refers to a server based on the operating environment. In this environment, the transmitted content is controlled intelligently.

The core content of SCORM is composed of three parts: content aggregation model (CAM), runtime environment (RTE), sequencing and navigation (SN). The purpose of CAM is to provide a common method, which can change the learning resources into learning content. The main content of RTE processing will object to the learner's browser (such as release of learning content). The content object can communicate with the LMS if necessary. How to communicate with each other, what kind of information should be track, and how to manage these LMS information are controlled by RTE information. The SN can make the LMS provide learning content according to the learners' selection and learning schedule in run time.

\section{The design and development of interactive courseware}

The interactive courseware of distance learning system is composed of two parts: learning management system and courseware.

\subsection{The working principle of interactive courseware based on SCORM standard.}

CAM is a standard package of learning content, which can be understood as the criteria for making courseware. The running time environment is the transmission mechanism of the learning content and general data model, and it can be understood as the standard learning management system. Sorting and navigation standard presentation of learning content can be understood as a process with a specific learning activity. It also needs design according to the needs of teaching in different courseware steps. It should be pointed out that the same learning content is applied to the teaching activities of different levels and different objects.

\subsection{The development of learning management system based on SCORM standard.}

Learning management system can be applied to not only the relatively simple CBT classroom, but also the more complex remote network learning environment. In the learning management 
system, students can do things as learning, curriculum module communication, questioning, self testing, homework, exam and other learning activities through the browser. The teacher can manage the learning content, track student learning progress and acquisition of knowledge. The key step of interactive transmission and operation of learning content are monitored, and the learning content for students for the next step is also determined by this system.

The purpose of SCORM is to learn the resources that can be reused in different learning management systems and to be interoperable with each other. So a common way to start learning resources is needed, and there must be a common mechanism for the exchange of learning resources and learning management system. In order to have a predefined language and vocabulary to form the basis of this communication, the SCORM standard builds the foundation from three aspects: the operation, application programming interface, data model. The SCORM standard provides a number of networks teaching platform interface in addition to the interface with the courseware, and the data model used in its communication. In the course, the starting and entering of the data and the information, the identification of the participants and the experiment are included.

\subsection{The courseware development based on SCORM standard.}

The task of the Courseware maker is to choose the micro unit, Sharable Content Object (SCO), and combines the SCO in accordance with the curriculum objectives, teaching needs, and then packages and releases them, culminating in the learning management system to carry out teaching activities [5].

\subsubsection{Elements of SCORM courseware.}

SCORM courseware is composed with four elements: the micro unit, the shared content object, the content of the organization structure, metadata. SCO is not only the most basic courseware editing software units, but also the platform to organize and track the smallest units, and each SCO must have a complete description of the metadata. The metadata information module can be divided into nine categories, and each category can be subdivided in other items. There are a lot of tools to make common metadata, but the most convenient and efficient tool for software is Reload Editor.

\subsubsection{SCORM courseware package.}

Referring to the requirements of CAM design network courseware, the key element here is how to complete the package of courseware content. Packaged SCORM courseware is known as the content package, it provides students, teachers, learning management system to provide the use and management of the content of the standard method of learning. A content package consists of two main parts: contents list and physical file.

Content list is a XML file, the default file name is imsmanifest.xml, placed under the root directory of the package. The content list contains the organization and presentation of one or more static learning resources. A complete list of contents includes the following parts: 1: the overall description of the contents of metadata packets; the content of organizational structure: structure or structure includes one or more teaching unit composed of independent learning resources; resources: define the content package binding learning resources; the contents of the list description: the teaching unit of any nested logic (can be used as an independent unit). Physical file is the actual course content, media, evaluation, XML namespace definition, and some other documents.

\section{Resolution techniques}

Resolution of imsmanifest.xml list file is the core technology in SCROM courseware. The analysis of the SCORM courseware package is the core part of the network courseware making platform based on SCORM standard. XML file is a data carrier, one of its important applications is as a data transfer tool, but also the way to communicate between the program, which must handle the application program on the XML document reading and writing problems.

$\mathrm{XML}$ document is a structured document. If you want to use the general document $\mathrm{I} / \mathrm{O}$ application directly to the XML document operation, the complexity of programming and efficiency 
is low. So XML is analyzed by the XML parser document structure, the results of the analysis through the interface provided by the parser to achieve access, in fact, is indirectly on the operation of the XML document. That is to say the XML parser is to build a bridge between XML and application, its main function is to check if the XML file has errors in the structure, mark peel in the XML file from the analysis of useful data, then give the application to the next step of the process. The existence of the parser makes the technical staff from the tedious work of the low level of liberation, different parser often have different operation interface, the interface represents the operation method.

Today, the commonly used XML parsers include the following: DOM, SAX, JDOM, dom4j. Each of these four kinds of parser has its advantages and disadvantages, and it should be based on the actual choice of the development of one or some combination of analysis. For the JAVA language, the first Dom4j parser, it is the biggest advantage of simple, easy to use and high. Secondly, using Dom4j oriented programming interface to parse XML document, with Dom4j API and standard DOM interface with parallel access function, compared with the JDOM method is more flexible, application oriented programming interface, but do not care about the underlying implementation of the interface, and allows the bottom of Dom $4 \mathrm{j}$ in the different parsing mechanisms see free switch. And Dom4j to the original bottom of the parser for a high degree of encapsulation using the method of abstract basic class more simplified the processing of XML documents.

\section{Conclusion}

In the system of higher occupation education, the distance education is the mainstream direction of its development, and the development of shared, reusable educational resources and contains interactive courseware description of teaching sequence is an important direction for the development of distance education. In the production of ideas and methods of studying the content organized, the interactive courseware based on SCORM is more flexible, and enhances the portability of the courseware, which is different from the traditional courseware to obtain advantages and versatility, and it is more suitable for the characteristics of network learning and to seek and carry out tailored standardization learning tools.

\section{References}

[1] Chang Ling, Peng Guojian. Design and implementation of network multimedia courseware based on SCORM standard [J]. Journal of University of South China, 2008 (3): 41-43.

[2] Yu Shengquan. The international standard of SCORM E - Learning [J]. Distance educational education of China, 2003 (5):25-27.

[3] Huang Zongjiang, Wang Zhaoqing. Design of network courseware based on SCORM standard [J]. Journal of Zhejiang Sci-Tech University, 2008 (1): 70-74.

[4] Lu Zheng, Yang Luming, Song Hong. The development and implementation of teaching management platform based on SCORM standard [J]. Computer and digital engineering, 2005 (3): 81-84.

[5] Zhu Xinhua, Luo Hui. Design of open content object and its operating environment based on SCORM [J]. Computer engineering and design, 2005 (11):2949 2951.

[6] Cai Qunying. The implementation technology of the content package production tools conforming to the specification SCORM [J]. Computer system application, 2007 (8):43 - 47. 